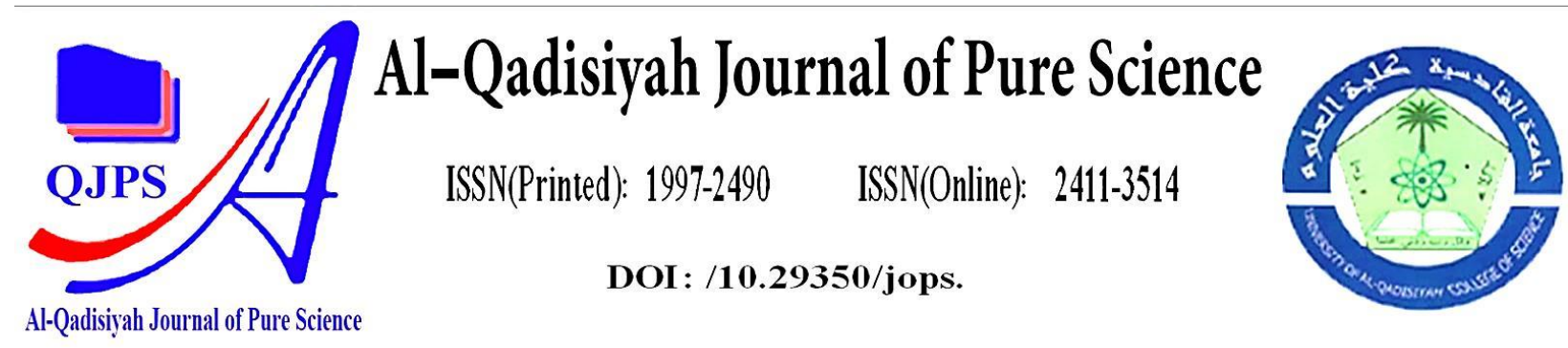

http://qu.edu.iq/journalsc/index.php/JOPS

\title{
Enhance the gas-sensing performances of graphene oxide (G0) thin films for detecting nitrogen dioxide gas
}

\begin{tabular}{|c|c|}
\hline \multirow{2}{*}{$\begin{array}{l}\text { Authors Names } \\
\text { a. Ali Al-Jawdah } \\
\text { b. Rathyeah Jarah } \\
\text { c. Mohsin Al-Khaykanee } \\
\text { d. Mirjam Skof }\end{array}$} & ABSTRACT \\
\hline & $\begin{array}{l}\text { In this work, graphene oxide (GO) synthesized via a modified Hummer } \\
\text { method was utilized to manufacture thin films for gas sensor applications. } \\
\text { The films were prepared on glass substrates using the spin coating }\end{array}$ \\
\hline Article History & $\begin{array}{l}\text { technique, the concentration of GO was varied in the precursor liquid. The } \\
\text { crystall ographic properties of the prepared GO films were analyzed using }\end{array}$ \\
\hline Received on: $18 / 6 / 2021$ & XRD and the results showed a polycrystalline structure with a crystallite size \\
\hline $\begin{array}{l}\text { Revised on: } 30 / 7 / 2021 \\
\text { Accepted on: } 13 / 8 / 2021\end{array}$ & of $15.51 \mathrm{~nm}$. Using the weighing method, the average film thickness was \\
\hline $\begin{array}{l}\text { Accepted on: 13/8/2021 } \\
\text { Keywords: }\end{array}$ & $\begin{array}{l}\text { determined to be about } 200 \mathrm{~nm} \text {. UV-Vis absorption spectrometry combined } \\
\text { with the Tauc method confirmed the indirect nature (allowed and }\end{array}$ \\
\hline $\begin{array}{l}\text { Graphene oxide, gas sensor, } \\
\text { operating temperature, } \\
\text { response time, sensitivity. }\end{array}$ & $\begin{array}{l}\text { forbidden) of electronic transitions in the samples and it also showed a } \\
\text { decrease in the optical energy gap with an increasing amount of GO in the } \\
\text { samples. Values for Eg ranged from } 2.4 \mathrm{eV} \text { to } 2.15 \mathrm{eV} \text { for allowed transitions }\end{array}$ \\
\hline $\begin{array}{l}\text { DOI: } \\
\text { https://doi.org/10.29350/ } \\
\text { jops.2021.26. 4.1360 }\end{array}$ & $\begin{array}{l}\text { and trom } 3.05 \text { eV to } 2.6 \text { eV for torbidden transitions. Gas sensing } \\
\text { measurements were performed using } \mathrm{NO} 2 \text { as target gas at different } \\
\text { operating temperatures }(50,100,200 \text { and } 300 \mathrm{oC}) \text {, as well as four target gas } \\
\text { concentration ( } 100 \mathrm{ppm}, 400 \mathrm{ppm}, 700 \mathrm{ppm} \text {, and } 1000 \mathrm{ppm} \text { ) have been } \\
\text { tested and shows the good response in the range of } 10 \% \text {. It can be seen that } \\
\text { the sensitivity increases with increasing operating temperature and gas } \\
\text { concentration. At } 300 \mathrm{oC} \text { operating temperature response and recovery time } \\
\text { decrease to their lowest value or } 2.6 \text { and } 5 \text { seconds, respectively. }\end{array}$ \\
\hline
\end{tabular}

\section{Introduction}

The technological improvement as well as growing environmental and health concerns have generated significant interest in detection of toxic and hazardous gases and the development of sensing equipment. Gas sensors are devices that convert a given gas concentration into the corresponding electrical signal. Sensors play an important role in a variety of industries and applications, such as chemical processing, environmental monitoring, agriculture, public safety, and medicine. Rising global demand to provide the gas sensor with high sensitivity, high selectivity, fast response, low cost, low 
power consumption, high stability, and portability has led to the search for new gas-sensing materials. [9-6]. Graphene, first described by Geim and Novoselov [19], exhibits a particularly intriguing twodimensional structure consisting of sp2 hybridized carbon atoms. Graphene is considered the thinnest material in the world [4], a one-atom-thick sheet forming a hexagonal lattice with a thickness of approximately $0.335 \mathrm{~nm}$, a carbon-carbon bond length of $0.142 \mathrm{~nm}$, and a bond angle of $120^{\circ}$.

The distinctive structure of graphene gives rise to its unique properties, such as excellent thermal and electrical conductivity, high strength and it further allows for the quantum Hall effect to be observable at room temperature. Additionally, graphene features a large surface area which is beneficial for adsorption [25].

The oxidized form of graphene (GO) is also a two-dimensional material with oxygen functional groups. The large interest in this material is a result of its exceptional properties. The presence of oxygen functional groups makes graphene oxide hydrophilic and allows it to be dispersed in aqueous solutions. This allows for easy processing when combining it with other materials in order to improve electrical and mechanical properties [24]. Furthermore, the size of the graphene oxide layer can be tuned from $\mathrm{mm}$-range down to a few $\mathrm{nm}$. This tunability of both its flake size and chemical composition through doping makes graphene oxide an attractive material in many fields such as electronic applications, composite materials, clean energy devices, biology, and medicine [2].

It was found in both, experimental and theoretical work [5], that graphene and its derivatives, such as graphene oxide, present not only a large specific surface area facilitating the gas molecules adsorption, but also an easily modifiable surface, allowing for the gas sensing ability to be tuned. Presently, there is an increased focus on enhancing the performance of graphene gas sensors using computational chemistry, composite materials, and micro-electro-mechanical systems.

\section{Sensing Properties}

Graphene has an electronic bandgap of zero. However, adding elements such that oxygen which results in formation of holes in the carbon lattice result in p-type semiconducting behavior [26]. This change in the Fermi level caused by p-type doping, on the one hand, causes a change in the adsorption energy, where the introduced holes cause an electron to pull effect towards atoms and molecules in the gas atmosphere, and the other hand it leads to changes in the electrical conductivity of graphene. This effect is sensitive not only to p-type but also n-type doping and makes graphene an ideal material to detect adsorbed gas molecules. Whether an adsorbed atom or molecule will act as a donor or an acceptor is determined by the relative position of the Fermi level of graphene compared to the valence band of the adsorbed species, e.g. is the Fermi surface of graphene lower than the valence band of the adsorbed molecule, it works as donor and when the Fermi surface of graphene is higher than the valence band, the adsorbed species works as acceptor [29]. The change in resistivity of graphene is dependent on the concentration of adsorbed species, which allows it to be used in field effect transistors (FET) and MEMS gas sensors. In those devices, a substrate, made of an insulating material, is coated with graphene as the gas-sensing material, and electrodes are deposited at both ends of the sensitive material. Most commonly, gas sensors operate in resistive mode, where the concentration of a certain gas is analyzed by directly measuring the change of resistance during interaction with a given atmosphere [8]. 


\section{Experimental Procedure}

In this work, graphene oxide (GO) was produced based on the modified Hummers method from pure graphite. $2.3 \mathrm{~g}$ of graphite and $1.2 \mathrm{~g}$ of sodium nitrate (NaNO3) were mixed, then $100 \mathrm{ml}$ of sulphuric acid $\left(\mathrm{H}_{2} \mathrm{SO}_{4}\right)$ and 0.005 gm of boric acid $(\mathrm{H} 3 \mathrm{BO} 3)$ were added and the mixture was stirred over an ice bath for $15 \mathrm{~min}$. This was followed by progressively adding $5 \mathrm{gm}$ of potassium permanganate $\left(\mathrm{KMnO}_{4}\right)$ while maintaining the temperature at $0^{\circ} \mathrm{C}$. The resulting solution was stirred for 2 more hours until it turned dark green. This mixture was left for another 2 hours to react, then the temperature was raised to $40^{\circ} \mathrm{C}$ for $30 \mathrm{~min}$. Then, $100 \mathrm{ml}$ of deionized water was slowly added, together with a rapid temperature increase to $100^{\circ} \mathrm{C}$. After 5 minutes, the solution was treated with $7.5 \mathrm{ml} \mathrm{H} 2 \mathrm{O} 2$ before being washed and rinsed with deionized water and a $5 \% \mathrm{HCl}$ solution. Finally, the reaction product was dried at $60^{\circ} \mathrm{C}$, resulting in powdered graphene oxide.

Preparing GO concentrations have been doing it by solving $(0.1,0.2,0.3$, and $0.4 \mathrm{gm})$ of graphene oxide and in (10) $\mathrm{ml}$ of the deionized water and mix them using a magnetic stirrer to get a homogeneous solution. The spin coating method was used to deposit GO thin films on a glass substrate equipped with a grid of aluminum electrodes, Figure 1. Time and spin speed were adjusted to get a homogeneous film with the required thickness. Determination of film thickness was performed by using the weighing method according to the following formula:

$$
t=\frac{\Delta m}{\rho A}
$$

Where $\Delta \mathrm{m}$ is the mass difference of the substrate before and after the deposition process, A $(25 \mathrm{~mm} \times 15 \mathrm{~mm})$ is the coated area and $\rho(0.44 \mathrm{gm} / \mathrm{cm} 3)$ is the mass densit

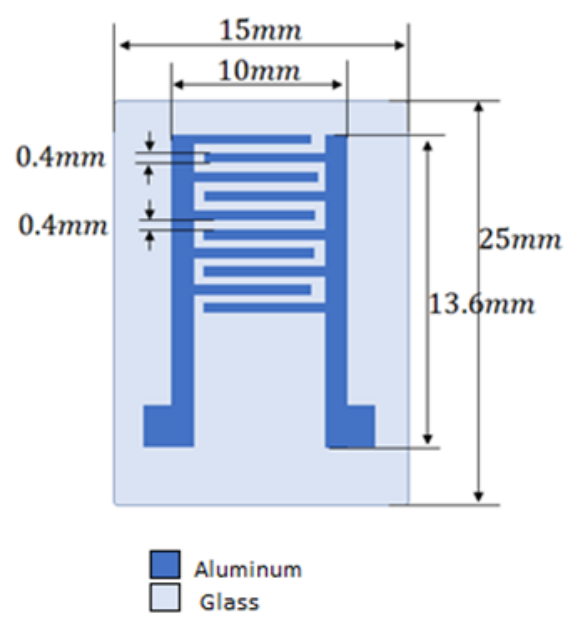

Figure. 1: A Schematic diagram of aluminum electrode grid deposited on the sensor substrate (glass). 
X-ray diffraction (wavelength $\lambda=1.5406 \mathrm{~A}$ ) was utilized to gather crystals graphic information about the GO films. The distance between adjacent lattice planes (d) was calculated using the Bragg equation $[17,21]$;

$$
n \lambda=2 d \sin \theta
$$

The diffraction pattern shown in Figure 2 was used to determine the average crystallite size (D) according to the Scherrer equation $[11,6]$;

$$
D=\frac{0.9 \lambda}{\beta \cos \theta}
$$

Where $\lambda$ is the $\mathrm{X}$-ray wavelength, $\theta$ is the Bragg angle and $\beta$ is the line broadening at full-width halfmaximum (FWHM).



Figure. 2: $\mathrm{X}$-ray diffraction pattern for thin GO films deposited on glass.

UV-vis absorption spectroscopy measurements were performed with a UV-1650PC Shimadzu spectrophotometer to estimate the energy gap. Light intensity attenuation across the film follows the Lambert-Beer law [16,11];

$$
I=I_{0} e^{-\alpha x}
$$


Where I and Io are the intensity of light before and after passing through the film, $\alpha$ is the absorption coefficient and $\mathrm{x}$ the film thickness.

The data of absorption coefficient versus wavelength shown in (Figure 3) were used to estimate the optical energy gap (Eg) using Tauc's equation [1,13]:

$$
(\alpha h v)=B\left(h v-E_{g}\right)^{1 / r}
$$

Where B is the Tauc constant, hv is the photon energy, $\alpha$ is the absorption coefficient, $r$ is a constant related to the density of states distribution and indicates the type of transition so that its value will be equal to $1 / 2$ for direct allowed transitions and $3 / 2$ for direct forbidden transitions, while $n$ takes a value of 2 for indirect allowed transitions and 3 for indirect forbidden transitions.

The energy band gap describes the difference in energy between the bottom of the conduction band and the top of the valence band, thus band gap tuning is an important factor to optimize the performance of the optoelectronic materials [28].

\section{Results}

The thickness of the films was calculated using equation 1, an average of $200 \mathrm{~mm}$ film thickness was chosen. After applying the top electrodes, the films were transferred into the manufactured gas sensor testing system is shown in Figure 1. The bias voltage was set to 10 volts and the chamber pressure was chosen to be in the range of $1 \times 10-2$ bar. A flow meter was used to control the desired gas/air ratio in the testing chamber. To connect the sensor to the electric circuit, aluminum electrodes were thermally deposited on the coated slides via a thermal evaporation system (Edwards E306A Coating System). The electrode pattern is illustrated in Figure 2, its shape is designed to provide the maximum possible contact area between the electrode and the sensing material. The response of sensor towards exposure to gas has been checked by calculating the sensor sensitivity (S) which is defined as [22]:

$$
S=\frac{R_{g a s}-R_{o}}{R_{o}} \times 100 \%
$$

Where R_gas and R_o are the resistances of the sensor when exposed to the target gas (NO2) and without gas respectively.

The XRD diffraction pattern shown in Figure 3 confirms the polycrystalline nature of the GO films. The most prominent peak at 2 theta angles of $11.6^{\circ}$ reveals a crystallite size of $15.51 \mathrm{~nm}$ and a $\mathrm{d}$ space of $0.75 \mathrm{~nm}$. These results are in good agreement with (00-024-0072), International Center for Diffraction Data (ICDD) cards, and other published articles, [20,15]. The Tauc method, described in equation 4 , allows for the calculation of the energy bandgap using data gained from optical absorbance 
spectra. Where the optical absorption strength is dependent on the difference between the energy band gap and photon energy. The value of the exponent depends on the nature of the electronic transition, which can be either direct or indirect. The calculated values for $\llbracket(\alpha \mathrm{hv}) \rrbracket \wedge(1 / 2)$ and $\llbracket(\alpha \mathrm{hv}) \rrbracket$ $\wedge(1 / 3)$ versus $(h v)$ were plotted in Figures (4 and 5). In the calculations, the value of the exponent was chosen in order to provide the best fit and thus helps in identifying the type of transition. The energy band gap $(\mathrm{Eg})$ for each sample was determined via the intercept of the linear portion of each curve with the $\mathrm{h} v$ axis. The obtained values for the energy gap compared with the different amount of GO are listed in Table (1). It is worth noting that a decrease in the optical energy gap with an increasing weight percentage of GO in the sample can be seen, which can be resulting from an increase in the available energy localized levels near the band edges. These results are in agreement with [12].


Figure. 3: Variation ( $\alpha$ hv)1/2 versus hv, for allowed indirect transition (a), for forbidden indirect transition (b), at different amount of GO in the sample. 
Table 1: The values of energy gap for the allowed and forbidden indirect transitions compared to varying amount of GO.

\begin{tabular}{|c|c|c|}
\hline \multirow{2}{*}{ GO (wt\%) } & \multicolumn{2}{|c|}{ Energy gap (eV) } \\
\cline { 2 - 3 } & Allowed & Forbidden \\
\hline 1 & 2.4 & 3.05 \\
\hline 2 & 2.31 & 2.91 \\
\hline 3 & 2.25 & 2.77 \\
\hline 4 & 2.15 & 2.60 \\
\hline
\end{tabular}

\section{Gas Sensing Tests}

The gas sensing tests were performed in a gas chamber, which was manufactured from acrylic plastic and heated using a small ceramic heater connected to a temperature controller. The chamber is supplied with the target gas (NO2) and air using two mass flow meters, set to a constant flow of $1000 \mathrm{sccm}$ during the sensing measurements. A current source (2400 Source Meter, Keithley, Cleveland, Ohio, USA) was joined to a computer and used to measure the electrical resistance of the samples. The change in resistance in the GO films resulting from adsorbed gas molecules was translated into an electrical signal by the sensor and could be used to detect or calculate the target gas concentration. The measurement set-up is shown in Figure 4.

Measurements were conducted for the target gas (NO2) concentrations in a preset range (100 ppm, 400 ppm, $700 \mathrm{ppm}$, and $1000 \mathrm{ppm}$ ) and various operating temperatures (50,100, 200, and 300oC), which is defined as the temperature where the resistance reaches a constant value. Figure 6 shows the variation of sensor sensitivity to operating temperature and it can be seen that the sensitivity increases with increasing operating temperature to an optimum of $250 \mathrm{oC}$, that can be interpreted as due to the increased reaction rate between the sample surface and target gas. The response and recovery times of the sensor as a function of operating temperature for the sample with $4 \%$ concentration of GO are shown in Figure 5. Both, response and recovery time of this sensor decrease with increasing operating temperature, down to the lowest responsive and recovery time of about $2.6 \mathrm{~s}$ and $5 \mathrm{~s}$, respectively. 
Table (2): Response and recovery time vs graphene oxide concentration.

\begin{tabular}{|c|c|c|}
\hline GO wt\% & Response time (s) & Recover time (s) \\
\hline 1 & 7.3 & 25.2 \\
\hline 2 & 5.2 & 20.3 \\
\hline 3 & 4.4 & 17.2 \\
\hline 4 & 2.6 & 05.0 \\
\hline
\end{tabular}

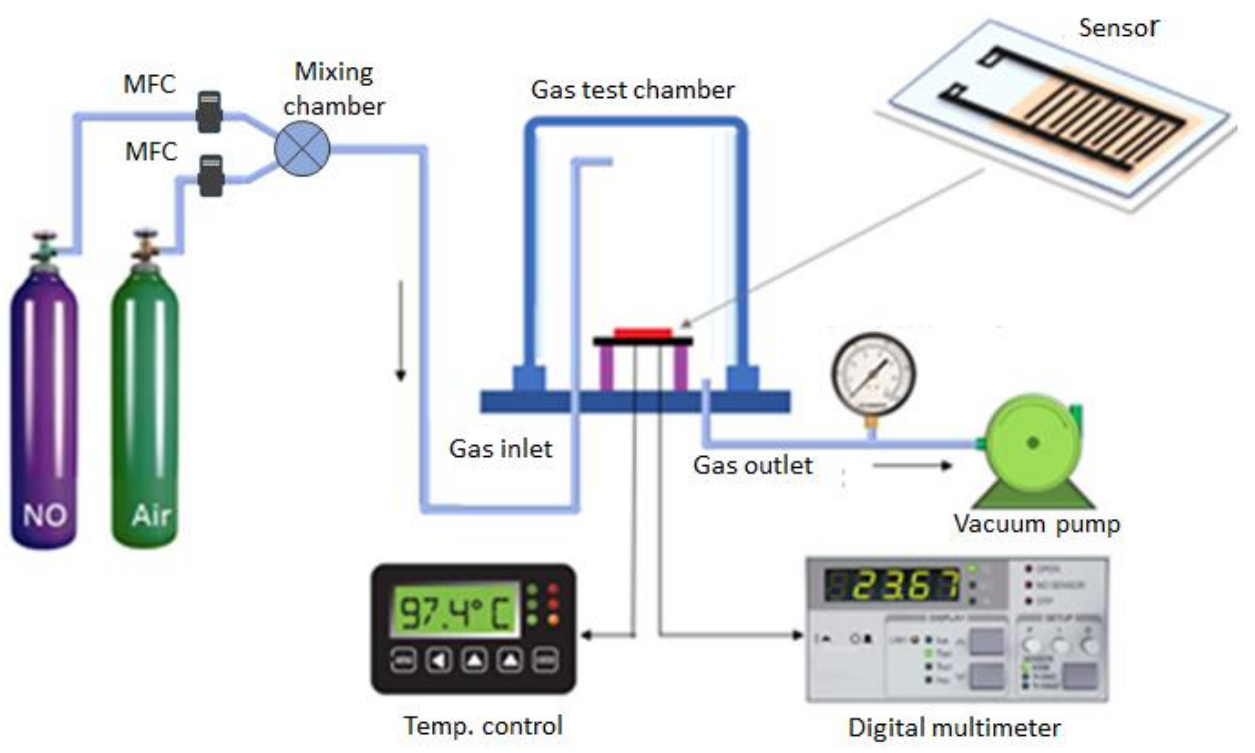

Figure. 4: Experiment setup, gas sensor testing system. 


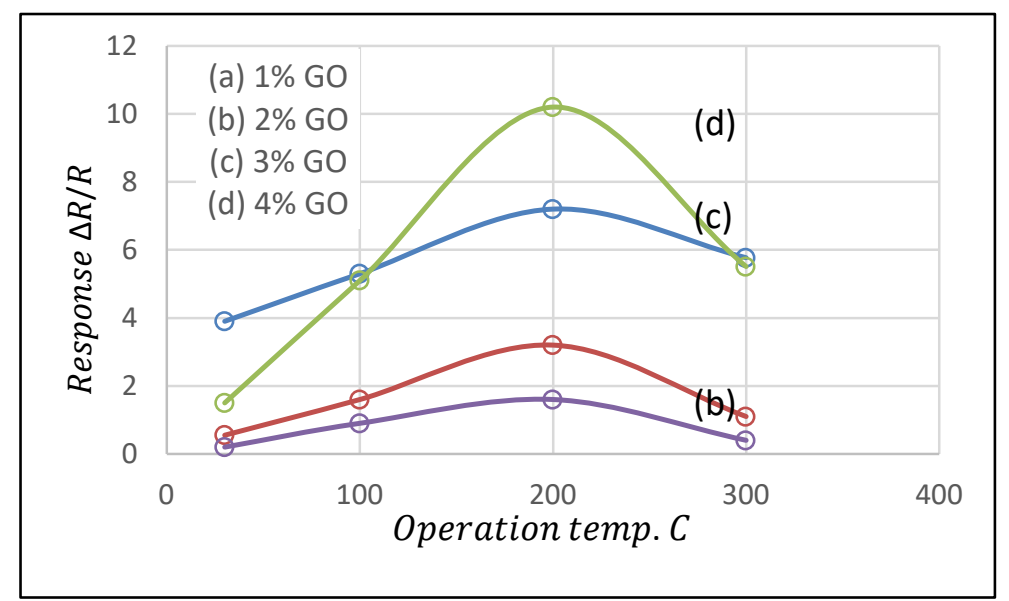

Figure. 5: Variation of sensor sensitivity for NO2 with operating temperature for different percent of GO

Figure 6 indicates a rapid increase in the sensor response with NO2 gas concentrations. This level of sensitivity and performance make it favorable material to make reliable sensor. The high sensitivity and fastest response times could be realized at a gas concentration of $1000 \mathrm{ppm}$, which is in good agreement with $[14,10]$. NH3 acts as an electron donor on graphene. Therefore, when the GO film is exposed to NH3 molecules, electrons will be easily transferred to GO thin film, thereby reducing the number of conductive holes and, thus increasing the electrical resistance of GO film. While, NO2 gas and graphene working together as an electron acceptor. When the surface of graphene absorbs No2 molecule, electrons will be transferred from the graphene to the NO2 molecule, which lead to increases the hole concentration in the graphene and therefore decrease the resistance [7].



Figure. 6: The dependence of GO sensor sensitivity on NO2 gas concentrations. 


\section{Conclusion}

In this work, the influence of varying amounts of graphene oxide (GO) (1-4 wt $\%$ ) on the performance of thin film gas sensors have been investigated. Properties analyzed were sensitivity, response and recovery time. The thin film samples have furthermore undergone XDR analysis and UV-Vis spectroscopy. XRD diffraction patterns revealed a polycrystalline structure of GO. Moreover, the most prominent peak at a 2 theta angle of $10.6^{\circ}$ was used to calculate the crystallite size using the Scherer equation. The results indicate a crystallite size of $15.51 \mathrm{~nm}$ in the films. Tauc analysis of the optical absorption spectra shows that the electronic transition is indirect and the energy gap about $2.4 \mathrm{eV}$ to $2.15 \mathrm{eV}$ for allowed transitions and from $3.05 \mathrm{eV}$ to $2.6 \mathrm{eV}$ for forbidden transitions. The GO films exhibited good sensitivity and selectivity to the target gas, NO2. The quickest response-recovery characteristics (2.6 and $5 \mathrm{~s}$, respectively) and the highest sensitivity were found at 200oC operating temperature. Finally, the findings in this work and encouraging results in using GO thin films to accurately sense NO2 gas suggest that more research into the improvement and production of such sensing devices is needed.

\section{References:}

[1] Baishya, K., Ray, J. S., Dutta, P., Das, P. P., \& Das, S. K. (2018). Graphene-mediated band gap engineering of WO 3 nanoparticle and a relook at Tauc equation for band gap evaluation. Applied Physics A, 124(10), 704.

[2] Banerjee, A. N. (2018). Graphene and its derivatives as biomedical materials: future prospects and challenges. Interface Focus, 8(3), 20170056.

[3] Berger, C., Song, Z., Li, X., Wu, X., Brown, N., Naud, C., ... \& Conrad, E. H. (2006). Electronic confinement and coherence in patterned epitaxial graphene. Science, 312(5777), 1191-1196.

[4] Cao, M. S., Wang, X. X., Cao, W. Q., \& Yuan, J. (2015). Ultrathin graphene: electrical properties and highly efficient electromagnetic interference shielding. Journal of Materials Chemistry C, 3(26), 6589-65

[5] Chatterjee, S. G., Chatterjee, S., Ray, A. K., \& Chakraborty, A. K. (2015). Graphene-metal oxide nanohybrids for toxic gas sensor: a review. Sensors and Actuators B: Chemical, 221, 1170-1181.

[6] Drits, V., Środoń, J., \& Eberl, D. D. (1997). XRD measurement of mean crystallite thickness of illite and illite/smectite: Reappraisal of the Kubler index and the Scherrer equation. Clays and clay minerals, 45(3), 461-475.

[7] Fei, H., Wu, G., Cheng, W. Y., Yan, W., Xu, H., Zhang, D., ... \& Wu, H. C. (2019). Enhanced NO2 sensing at room temperature with graphene via monodisperse polystyrene bead decoration. ACS omega, 4(2), 3812-3819.

[8] Fine, G. F., Cavanagh, L. M., Afonja, A., \& Binions, R. (2010). Metal oxide semi-conductor gas sensors in environmental monitoring. sensors, 10(6), 5469-5502.

[9] Geim, A. K., \& Novoselov, K. S. (2010). The rise of graphene. In Nanoscience and technology: a collection of reviews from nature journals (pp. 11-19).

[10] Groß, A., Beulertz, G., Marr, I., Kubinski, D. J., Visser, J. H., \& Moos, R. (2012). Dual mode NOx sensor: Measuring both the accumulated amount and instantaneous level at low concentrations. Sensors, 12(3), 2831-2850. 
[11] Holzwarth, U., \& Gibson, N. (2011). The Scherrer equation versus the'Debye-Scherrer equation'. Nature nanotechnology, 6(9), 534-534.

[12] Joseph, S., John, A. O., Mugwang'a, F. K., \& Katana, G. G. (2019). Tuning the band gap energy of reduced graphene oxide using biopolymer chitosan for high power and frequency device applications. American Journal of Polymer Science \& Engineering, 7(1), 8-19.

[13] Li, X., Zhu, H., Wei, J., Wang, K., Xu, E., Li, Z., \& Wu, D. (2009). Determination of band gaps of self-assembled carbon nanotube films using Tauc/Davis-Mott model. Applied Physics A, 97(2), 341-344.

[14] Mahendia, S., Tomar, A. K., \& Kumar, S. (2010). Electrical conductivity and dielectric spectroscopic studies of PVA-Ag nanocomposite films. Journal of Alloys and Compounds, 508(2), 406-411.

[15] Malmonge, L. F., \& Mattoso, L. H. (1995). Electroactive blends of poly (vinylidene fluoride) and polyaniline derivatives. Polymer, 36(2), 245-249.

[16] Mäntele, W., \& Deniz, E. (2017). UV-VIS absorption spectroscopy: Lambert-Beer reloaded.

[17] Monshi, A., Foroughi, M. R., \& Monshi, M. R. (2012). Modified Scherrer equation to estimate more accurately nano-crystallite size using XRD. World journal of nano science and engineering, 2(3), 154-160.

[18] Novoselov, K. S., Geim, A. K., Morozov, S. V., Jiang, D., Zhang, Y., Dubonos, S. V., \& Firsov, A. A. (2004). Electric field effect in atomically thin carbon films. science, 306(5696), 666-669.

[19] Panchakarla, L. S., Subrahmanyam, K. S., Saha, S. K., Govindaraj, A., Krishnamurthy, H. R., Waghmare, U. V., \& Rao, C. N. R. (2009). Synthesis, structure, and properties of boron-and nitrogen-doped graphene. Advanced Materials, 21(46), 4726-4730

[20] Park, S., An, J., Potts, J. R., Velamakanni, A., Murali, S., \& Ruoff, R. S. (2011). Hydrazinereduction of graphite-and graphene oxide. carbon, 49(9), 3019-3023

[21] Pope, C. G. (1997). X-ray diffraction and the Bragg equation. Journal of chemical education, 74(1), 129.

[22] Pustelny, T., Setkiewicz, M., Drewniak, S., Maciak, E., Stolarczyk, A., Urbańczyk, M., ... \& Strupinski, W. (2013). The sensibility of resistance sensor structures with graphene to the action of selected gaseous media. Bulletin of the Polish Academy of Sciences. Technical Sciences, 61(2), 293-300.

[23] Saxena, S., \& Tyson, T. A. (2010). Interacting quasi-two-dimensional sheets of interlinked carbon nanotubes: a high-pressure phase of carbon. ACS nano, 4(6), 3515-3521.

[24] Shams, M., Guiney, L. M., Huang, L., Ramesh, M., Yang, X., Hersam, M. C., \& Chowdhury, I. (2019). Influence of functional groups on the degradation of graphene oxide nanomaterials. Environmental Science: Nano, 6(7), 2203-2214.

[25] Smith, A. T., LaChance, A. M., Zeng, S., Liu, B., \& Sun, L. (2019). Synthesis, properties, and applications of graphene oxide/reduced graphene oxide and their nanocomposites. Nano Materials Science, 1(1), 31-47

[26] Stankovich, S., Dikin, D. A., Piner, R. D., Kohlhaas, K. A., Kleinhammes, A., Jia, Y., ... \& Ruoff, R. S. (2007). Synthesis of graphene-based nanosheets via chemical reduction of exfoliated graphite oxide. carbon, 45(7), 1558-1565. 
[27] Stavn, R. H. (1981). Light attenuation in natural waters: Gershun's law, Lambert-Beer law, and the mean light path. Applied optics, 20(14), 2326_1-2327.

[28] Xiao, Z., Zhou, Y., Hosono, H., Kamiya, T., \& Padture, N. P. (2018). Bandgap optimization of perovskite semiconductors for photovoltaic applications. Chemistry-A European Journal, 24(10), 2305-2316. 